\title{
Report
}

\section{The National Scientific Conference of the Solicitors' Professional Self-government The Constitution in a Democratic State, Poznań, 21-22 October 2016}

The National Scientific Conference of the Solicitors' Professional Self-government on the issue of 'The Constitution in a Democratic State' took place in Poznan (Poland) on 21-22 October this year. This event was an opportunity for a common discussion of legal practitioners and academics on the matter, which is subject of current interests in contemporary Poland again.

The Conference's agenda had predicted six separate panels, which consisted of mini lectures of academics and a discussion. These discussions, in which each member of the publicity could take part, met with the highest level of interest and sometimes equally high emotions.

The opening speeches of hosts' representatives defined the main issue of considerations being made during the Conference. Firstly, it was said, that the problem of assigning primacy of political will upon the applicable legal order is once more current in Polish reality. Secondly, the common voice of legal professionals (both academics and practitioners) shall be heard by the authority and revived their inaccurate views on the state and constitutional law order.

The first panel was devoted to the issue of government system in Poland from the perspective of the model of executive power ${ }^{1}$. In accordance to the

Moderator of this panel was prof. J. Ciapała (University of Szczecin). The panellists were: prof. D. Dudek (Catholic University in Lublin), prof. S. Patyra (Maria Curie-Skłodows- 
moderator's thesis that the expression 'executive power' is rather inappropriate to contemporary state order conditions, prof. D. Dudek emphasized that the classical separation of powers, based on the Montesquieu's theory, is wrong. Not only because it has to be completed by the principle of power's cooperation, but moreover it shall be reduced to dual-separation. The Sejm, the Senat and the Council of Ministers (with its administration) shall be collectively called and regarded as politically-creative power, while courts, tribunals and the Ombudsman shall be collectively understood as power of control and protection. In fact, the Polish state system functions in such shape. The next lecturer prof. S. Patyra said, that the previous evolution of Prime Minister's office indicates, that without his strong and autonomous position it is rather impossible to establish rationalized parliamentary cabinet system. The only practitioner in politics among the lecturers was prof. H. Suchocka, who emphasized that contemporary considerations upon the model of executive power are indeed searching for a model of good governance, which could not be effective without the creation of stable political and legal culture. The last lecturer was prof. M. Wiszowaty, who decided to show the problem of president's necessity in a parliamentary system, by leading the audience through the presidential myths (falsifying them). He concluded that in an American system a president is a central and obviously necessary element of the state structure, but in a parliamentary system it is not so obvious and a well-designed state could function without a head of state.

After these lectures, the discussion began. It focused on the most effective and stable version of state's power separation.

The second panel was devoted to the issue of the role and tasks of legislative power ${ }^{2}$. The first lecturer prof. R. Grabowski indicated that in the aspect of constitutional norms and standards the Sejm's position is stable, but in the political aspect it constantly changes a lot. This conclusion and all Sejm's relations to other state's authorities deny the legitimacy of a thesis that

ka University in Lublin), prof. H. Suchocka (Adam Mickiewicz University in Poznań) and prof. M. Wiszowaty (University of Gdańsk).

2 Moderator of this panel was prof. W. Orłowski (Maria Curie-Skłodowska University in Lublin). The panellists were: prof. R. Grabowski (University in Rzeszów), prof. M. Jabłoński (University of Wroclaw), PhD J. Juchniewicz (University of Warmia and Mazury in Olsztyn) and prof. A. Młynarska-Sobaczewska (Polish Academy of Science). 
the Sejm is omnipotent. An important element of Sejm's position is its legislative power, but in a democratic state it ought to be considered through the prism of citizens' impact on a legislative process. These issues were the essence of prof. M. Jabłoński's lecture, who analyzed all legal institutions which guarantee above-mentioned citizens' impact. However, the scope of them is rather wide, as only two are really effective - right of access to public information and freedom of assembly. Another aspect of the Sejm's position was analyzed by $\mathrm{PhD}$ J. Juchniewicz, who tried to explain practical issues of opposition co-executions of Sejm's control upon the rest of state authorities, mostly the Council of Ministers. She assessed that the opposition does not have any political or legal institutions, which allow to execute government responsibility. The only legal tool of a great effectiveness is a right of access to public information. It means that the opposition, when the government hold the support of the majority in a lower chamber, is in the position similar to the citizens. Closing remarks were made by prof. A. Młynarska-Sobaczewska, who considered some chosen aspects of parliamentary legislative process. She noticed two reasons of a dissatisfying standard of law and increasing amount of bills in Poland. The first is a sectoral way of preparing projects, which determines their lack of general coordination with a legal system, and the second - is a lack of juridification of legislator's position in acts of an appropriate legal position. These two issues create chaos in the process of legislation and influence the standard of law badly.

After these lectures, the discussion began. It came to the conclusion, that the legislators (and politicians also) shall remember not to prepare too much law and that the law is rather created by those, who applied it, than by those, who wrote it in legal provisions.

The third panel was devoted to the issue of the electoral law and elections $^{3}$. Thanks to the first speaker W. Hermeliński listeners could meet with the proposal of changes in Polish electoral law. An idea to change the composition of the State Electoral Commission from nine judges to three judges

3 Moderator of this panel was prof. A. Stelmach (University of Adam Mickiewicz in Poznań). The panellists were: W. Hermeliński (the Constitutional Tribunal judge and the Chairman of the State Electoral Commission), PhD K. Urbaniak (University of Adam Mickiewicz in Poznań) and prof. P. Uziębło (University in Gdańsk). Unfortunately prof. S. Gebethner (University of Warsaw) could not be present due to his health conditions. 
and six politicians was noted as the most important. A current construction guarantees a reliable electoral process, which is based on the judge's independence, which is fully appreciated by the Polish Constitutional Tribunal and the European Tribunal of Human Rights in a whole sequence of their judgements. The proposed changes will surely infringe this guarantee. Secondly, the lecturer showed some technical proposals, which inter alia predict a new way of voting by a special voting machines. After these strictly practical ideas, PhD K. Urbaniak presented a various thesis about one of the main principle of electoral law - the principle of proportionality. He indicated, how this principle could be realised and what kind of results its completion would create. Most of the listeners, who do not work with that issue daily, were rather surprised, how deeply a change in realization of this principle, which does not require amendments to the constitution, could modify results of the general elections. The next lecturer prof. P. Uziębło also presents the various aspects of another electoral principle, but this time - the principle of equality in elections. This principle was presented with the context of its origin and its references to the general principle of equality. He specified that the equality may be understood in two ways - in a real sense and in a potential sense. This distinction does not only have a theoretical importance, because each of them create other possibilities of shaping electoral regulations and these regulations will define a real power of a single vote in the process of global electoral decision's creation.

After these three lectures, the discussion began. The member of the publicity asked inter alia about other proposals of changes in the electoral law such as exclusion of prints and delivery of ballots from a scope of the Public Procurement Law Act of 2004.

The fourth panel was devoted to the most significant issue of constitutional judiciary's model ${ }^{4}$. It dealt with so called constitutional crisis raised at the turn of the $7^{\text {th }}$ and $8^{\text {th }}$ term of the Polish Parliament. One of the elements of this crisis a dispute on the way of electing constitutional judges, mostly resolving the issue of their choice by the Parliament of a previous term. The first

4 Moderator of this panel was prof. W. Eączkowski (the Constitutional Tribunal judge). The panellists were: prof. B. Banaszak (University of Zielonagóra), prof. M. Chmaj (SWPS University), prof. A. Dziadzio (Jagielonian University in Krakow) and J. Stępień (former Chairman of the Constitutional Tribunal). 
lecturer prof. B. Banaszak presented his own theory, which can be reduced to the statement that the process of constitutional judges' election is not only proceeded by the Sejm and does not finish within a vote, but also consists of a presidential decision of taking oath from elected judges. Moreover, the lecturer denied the possibility of electing judges to spare before the vacancy in the occurred. A very polemical speech to these was presented by prof. M. Chmaj (the second lecturer), who presented a proper analyse of the acts about the Constitutional Tribunal, proclaimed in 2015 and 2016, with a wide reference to the constitutional judiciary. The core of his thesis was an unambitious manner assumption that the Constitutional Tribunal was created as a defense for the Parliament before its own unconstitutional legislation. The next lecturer, prof. A. Dziadzio, referred to the so called constitutional crisis in the aspect of historical genesis of the constitutional judiciary. He emphasized specially that a very popular argument against the constitutional judiciary was its susceptibility to be politicized. This argument is still used in the public dispute, sometimes the Constitutional Tribunal encourages to make such statements by himself. The last lecturer was J. Stępień, who referred to B. Banaszak's speech. In his view, the thesis that the Chairman of the Constitutional Tribunal is not able to execute Tribunal's judgement is entirely improper, because all state's authorities shall enforce these judgements in their own scope of activity. It would be misunderstood to deny his competition to prevent admission to the rule of judges, who were chosen unlawfully, which had been finally decided by the Constitutional Tribunal.

After these lectures, a heated debate and controversy began. The main element of a dispute between the panelists and the public was the question of the legal basis of acts upheld by - on the one hand - the Constitutional Tribunal and its Chairman, and on the other - by the President and the Sejm of $8^{\text {th }}$ term. In spite of many ideas and solutions of this question, each party remained with their points of view.

The fifth panel was devoted to the issue of dimension of justice demanded model $l^{5}$. The first lecturer, prof. A. Bałaban, dealt with the problem of a prop-

5 Moderator of this panel was prof. A. Bereza (Maria Curie-Skłodowska University in Lublin). The panellists were: prof. A. Bałaban (University of Szczecin), J. Iwulski (Chairman of the Supreme Court), Ł. Piebiak (undersecretary of state in the Ministry of Justice) and prof. J. Sobczak (SWPS University). 
er legitimization of judiciary in the Polish constitutional law order. He concluded, that there is no need to look for its legitimacy in the way of appointing of judges to their positions, but by referring to the constitutional standards, which prejudice the direct legitimacy of judges from the will of the sovereign adopted in a constitutional referendum. Secondly, the lecturer suggested a change in the understanding of a constitutional term of 'Minister of Justice'. Nowadays the meaning suggests that the Minister has got some competences in relation to judges, when in reality he has and shall have only administrative power, which could not violate judges' independence. The next lecturer J. Iwulski who analyzed a position and competences of the Polish Supreme Court in a various aspects of its activity. As he noticed, there are four spheres of the Supreme Court's activity (supervision of the courts' case law, the disciplinary jurisdiction, recognition of appeals from decisions of the Minister of Justice, recognition of appeals from decisions of the National Council of Judiciary). They stabilized the Supreme Court's position and every single change in this matter could create dysfunctions of its activity. The third lecturer was Ł. Piebiak, who presented some proposals (prepared by the Ministry of Justice) in functioning of common courts. These changes are believed to lead to the exclusion of opportunism of judges holding senior position, but as the lecturer emphasized this kind of judges' behavior is potential. The last lecturer prof. J. Sobczak referred to this thesis saying that, it is an obvious attempt to limit the judge's independence. He also settled these ideas in the long history of more or less successful attempts of limiting the independence of the judiciary in Poland, taken from the last years of a previous age.

After these lectures, a heated debate began again. The great majority of listeners could not understand the preparing attempts of changes presented

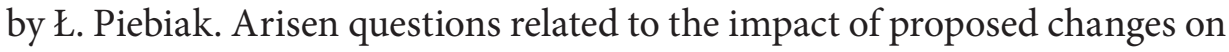
the independence of judges and reasons, which laid down as a basis of their creation. The speaker assured that there would not be any negative influence and avoided answering the second question.

The last panel was devoted to the issue of human rights and freedoms in the aspects of their protection ${ }^{6}$. Opening remarks were done by prof. A. Bryk, who

6 Moderator of this panel was prof. T. Gadkowski (University of Adam Mickiewicz in Poznań). The panellists were: prof. A. Bryk (Jagiellonian University in Kraków), prof. H. 
described some fundamental contentious points in the debate of constitutional judiciary. The lecturer disagreed with the thesis, that the constitutional courts consciously seek to expand their powers. In his view, it is a result of new, highly political problems subjected to their outcome. So the constitutional courts' activism is not their own fault. To this thesis referred prof. H. Izdebski, the next lecturer, who described a principle of proportionality as the most effective constitutional criterion of protecting human rights before their violation and limitation. The principle of proportionality, created in German administrative law doctrine and judiciary, is now a common denominator of liberal democratic states, which focused their strength on full actualization of freedom and human rights. The presentation of human liberties and rights protection would not be overall without the reflection of Islamic view on this matter. This view was presented by prof. M. Sadowski, who showed how differently from the European legal culture human rights are perceived in the Islamic legal culture. The lecturer also justified his interests in this matter, noting that it is the challenge of the modern legal world to take into account diversity of Islamic culture from the European one. We could not forget that the amount of Muslims in Europe raises and the need of common legal relation also increases (for instance by unknown problems of the right to marriage between Muslims and followers of other religions). The last lecturer was Z. Rudzińska-Bluszcz, who showed how so called constitutional crisis in Poland reflects on human rights' protection. She described some representative examples. The most interesting of them was the one, which sourced from the prevention of constraining of the Constitutional Tribunal's functions, which have to be upheld in its place by the common courts. These courts became the first and the last place to demand the constitutional justice by each entity.

The short discussion, concentrated on the influence of Islam culture on the European law, closed the conference. It is a common finding that the conference allowed to understand the rule of primacy of legal order upon each political will.

Jan Uniejewski University of Szczecin

Izdebski (SWPS University), prof. M. Sadowski (University of Wroclaw) and Z. Brudzińska-Bluszcz (Coordinator of Strategic Litigation in the Office of the Polish Ombudsman). 